\title{
Sob o casaco de Marx? A categoria da alienação no Serviço Social
}

\author{
Henrique Wellen ${ }^{1}$ \\ https://orcid.org/0000-0002-4787-5918
}

Julliane Trindade Oliveira ${ }^{2}$

https://orcid.org/0000-0001-9857-8801

\author{
Miliane Pinheiro Rocha ${ }^{2}$ \\ https://orcid.org/0000-0001-8256-0033
}

\footnotetext{
${ }^{1}$ Universidade Federal do Rio Grande do Norte, Centro de Ciências Sociais Aplicadas, Departamento de Serviço Social, Natal, RN, Brasil

${ }^{2}$ Universidade Federal do Rio Grande do Norte, Departamento de Serviço Social, Curso de Serviço Social, Natal, RN, Brasil
}

\section{Sob o casaco de Marx? A categoria da alienação no Serviço Social}

Resumo: A partir da seleção de 69 edições da Revista Katálysis e Serviço Social \& Sociedade, objetivou-se analisar as formas como a categoria da alienação foi utilizada em artigos destes periódicos. Foram identificados autores e obras teóricas que suportam os usos desta categoria e classificaram-se suas principais figurações a partir de quatro relações centrais: política, trabalho, subjetividade e metodologia. Autores integrantes da tradição marxista tiveram presenças destacadas, sem, contudo, referendarem uma fundamentação unívoca dessa categoria. O amplo escopo bibliográfico e heurístico apontou para usos relativos à coloquialidade e para a desconsideração concisa de precisão categorial.

Palavras-chave: Alienação. Serviço Social brasileiro. Marxismo. Trabalho. Subjetividade.

\section{In Marx's shoes: The category of alienation in Social Work}

Abstract: The study selected 69 issues of the journals Revista Katálysis and Serviço Social \& Sociedade to analyze how the category of alienation was used in the articles published. The research identified the authors and theoretical works that supported the use of alienation, and the most significant ways it was represented were classified based on four central aspects: politics, work, subjectivity, and methodology. The results showed the prominence of authors of Marxist tradition. These authors, however, did not agree on a univocal basis for the category of alienation. The broad bibliographic and heuristic scope pointed to uses related to colloquialism and to concise disregard of categorical precision.

Keywords: Alienation. Brazilian Social Work. Marxism. Labor. Subjectivity.

Recebido em 19.09.2018. Aprovado em 20.11.2018. Revisado em 29.04.2019.

\section{(ब) $(\odot$}

(C) O(s) Autor(es). 2019 Acesso Aberto Esta obra está licenciada sob os termos da Licença Creative Commons Atribuição-NãoComercial 4.0 Internacional (https://creativecommons.org/licenses/by-nc/4.0/deed.pt_BR), que permite copiar, distribuir e reproduzir em qualquer meio, bem como adaptar, transformar e criar a partir deste material, desde que para fins não comerciais e que você forneça o devido crédito aos autores e a fonte, insira um link para a Licença Creative Commons e indique se mudanças foram feitas. 


\section{Introdução}

Dentro das ciências sociais e humanas no Brasil, uma importante variação heurística se faz presente: tratase da diversidade teórica e metodológica da utilização da categoria da alienação. $\mathrm{O}$ termo alienação carrega, dentro de estudos desses campos de conhecimentos, uma gama de citações, de escopo relevado e que se relacionam com perspectivas teóricas e metodológicas distintas. Mesmo que a centralidade da utilização dessa categoria tenda a recair sobre a tradição marxista, destarte o fato de essa tradição preencher diversas perspectivas e autores, também é perceptível o uso de outras correntes teóricas, em especial daquelas advindas da psicanálise.

Essa categoria recebe, pois, uma miríade de definições que, a depender do autor que as subscreve, pode relacionar-se com mais proximidade ou não da sua acepção oriunda do trato do jovem Marx (2015) nos chamados Manuscritos Econômico-Filosóficos. Além disso, mesmo centrando-se na análise desse conjunto de anotações do jovem filósofo materialista, ainda se encontram distinções sobre a analítica da alienação. Isso se deriva do fato, essencialmente, de que a referida obra foi escrita, originalmente, como uma forma de estudos acerca da relação entre a sociedade capitalista e as suas contraposições advindas da propriedade privada dos meios de produção e da divisão social do trabalho.

Ademais, a aproximação, ainda tímida, do escritor alemão com os recursos teóricos e metodológicos posteriores (com destaque para a assimilação crítica da economia política inglesa) não permitiu que Marx (2015) alcançasse, nesse momento da sua formação, uma maior precisão expositiva e analítica dessa categoria. Conforme se observa na obra anteriormente citada, mesmo com um direcionamento crítico às determinações econômicas e concretas da ordem social matizada no capital, o jovem pensador de Trier ainda via-se enredado em resquícios filosóficos tanto de teor idealista hegeliano, como de teor antropomórfico, advindos, especialmente, da assimilação do pensamento de Ludwig Feuerbach ${ }^{1}$ (FREDERICO, 1995; GIANNOTTI, 1966).

O próprio teor das análises de Marx (2015) enunciadas nesse livro, consubstanciadas em forma de rascunhos e de passagens incompletas sobre o tema. indica a ausência, nessa obra, de um tratamento mais preciso acerca da categoria da alienação. Além disso, se é fato que o autor permaneceu fazendo uso dessa categoria nas suas obras maduras, não se pode desconsiderar que a sua abordagem recebeu outros recursos e abordagens. Por exemplo, ainda que Marx (1962), na sua obra publicada em 1867 (O Capital) faça uso desse termo, essa indicação não ocorre em simetria à sua obra juvenil, escrita entre 1843 e 1844 (Manuscritos Econômico-Filosóficos).

Ressalta-se que, no vernáculo original, essa categoria suporta, dentro das obras de Marx, três léxicos: Entfremdung, Entäußerung e Veräußerung. E, se as duas primeiras terminologias não apenas se aproximam mais de uma abordagem filosófica, como explicitam a sua maior presença na sua obra juvenil citada, o último termo tanto remete a uma análise econômica, como ocupa um uso mais destacado na sua obra madura. Em $O$ Capital (MARX, 1962), a alienação se aproxima de um movimento econômico de transferência ou troca de bens, análoga à alienação fiduciária. Um exemplo biográfico, que serve de expressão concreta para essa categoria, é o casaco de Marx, que, pelas recorrentes dificuldades financeiras do seu portador, ficou famoso pelas suas idas e vindas às casas de penhores. A oscilação econômica da família Marx determinava, portanto, a dinâmica de alienação de sua peça de roupa ${ }^{2}$.

Não obstante, tal problemática não se findou no interior da formação do pensamento de Marx nem nas distinções de traduções de suas terminologias ${ }^{3}$. Essa imprecisão virou um dissenso que, por seu turno, se consubstanciou em espaço e motivo para debates díspares acerca da relevância dessa categoria dentro do pensamento de Marx. Distante de uma unidade interpretativa dessa categoria, os analistas não somente se distanciaram acerca de um entendimento unívoco, como, em alguns casos, chegaram a estabelecer posições extremas e quase dualistas. Se, por exemplo, no caso de Althusser (1965), essa categoria, conforme argumenta o autor francês, deveria, pelo seu viés idealista, ser desconsiderada, para Fromm (1967), por outro lado, a alienação teria se mantido, até o final da vida de Marx, como a categoria central das suas análises.

Os ecos desta altercação também se fizeram e se fazem presentes dentro do Serviço Social brasileiro. Sejam em aulas, palestra, cursos ou demais espaços de formação, é bastante comum se observar a presença da categoria da alienação. Da mesma forma, em livros, artigos, ensaios ou outros tipos de textos, os usos dessa categoria também são bem perceptíveis. Em grande parte das vezes, visualiza-se que essas indicações orais e escritas buscam se referendar nos estudos e críticas que Marx realizou sobre o modo de produção capitalista. Com isso, se, de um lado, se estabelece uma mediação entre esses dois complexos - o pensamento marxista e o Serviço Social brasileiro - acerca da incorporação e da utilização da categoria da alienação, de outra forma, resta o questionamento acerca do grau e do teor desta vinculação, precisando-se quais as linhagens teóricas e metodológicas que estariam mais presentes nessas citações.

Diante disso, buscou-se desenvolver, inserido em um projeto de pesquisa que analisa as relações das obras de Karl Marx com o pensamento filosófico alemão da época iluminista, um plano de trabalho que objetivasse 
investigar os usos da categoria da alienação dentro do Serviço Social brasileiro. A referida pesquisa, que conta com o aporte de uma bolsa de pesquisa do Programa Institucional de Bolsas de Iniciação Científica (PIBIC), teve por objetivo central a análise, a partir de leituras e exames de autores e de obras centrais do Serviço Social brasileiro, de quais as principais formas de uso e de definições da categoria da alienação. O artigo, agora apresentado, refere-se a uma exposição sintética de alguns avanços dessa pesquisa.

\section{A categoria da alienação em periódicos do Serviço Social brasileiro}

\section{a) Procedimentos metodológicos:}

A partir da seleção de autores e de obras centrais do Serviço Social brasileiro, buscou-se identificar e precisar os usos e as definições que a categoria da alienação carrega. Foram três as etapas elegidas para a operacionalização da pesquisa: a seleção de textos e autores que citam a categoria da alienação; a identificação de definições e de usos dessas categorias nas obras e autores analisados, assim como das principais referências utilizadas; e a vinculação dessas análises com as definições originais, presentes no jovem Marx.

O plano de trabalho, que iniciou em agosto de 2017 e teve a primeira etapa findada em julho de 2018 , realizou-se por meio de uma pesquisa teórica, baseada em textos e autores selecionados, que utilizam ou atentam para definições acerca da categoria da alienação. O cotejamento e a comparação desse material foram precedidos pela classificação, a partir da tabulação de dados, em que se propôs, de forma resumida, indicar os principais usos e definições dessa categoria. Também se pautou a comparação analítica entre esses dados sintetizados e a obra que deu origem, dentro da tradição marxista, ao relevamento dessa categoria.

A amostra da pesquisa foi definida por artigos da Revista Katálysis e Serviço Social \& Sociedade. A escolha dessas duas revistas se deu tanto por motivos teóricos e profissionais, como por determinações metodológicas, de cunho operacional. Pelos limites da operacionalização da pesquisa, que foi realizada por uma equipe restrita a um professor e a duas alunas de graduação, decidiu-se circunscrever essa amostra para as duas revistas citadas. Em relação à importância teórica e profissional, ambas as revistas se destacam tanto como difusoras de novos conhecimentos e análises, por serem catalizadoras de perspectivas e valores políticos, assim como pela relevância incorporada a elas pelas agências de fomento brasileiras ${ }^{4}$. A partir da disponibilidade das revistas através de pesquisas na internet, foram selecionadas 40 edições da Revista Katálysis e 29 edições da revista Serviço Social \& Sociedade, perfazendo-se um total de 69 edições. A quantidade total de artigos da análise foi de 627, sendo 404 pertencentes à Revista Katálysis e 223 à Serviço Social \& Sociedade. Foram realizados os downloads dos artigos que estavam disponíveis nos websites das revistas e, com buscas textuais das terminologias estudadas, se observou a presença da categoria analisada em 121 artigos.

É importante frisar que, para melhor abarcar a variação heurística aportada pela categoria da alienação, resolveu-se incorporar também outros léxicos que, a depender da matriz teórica suportada, se constituem por relações diretas e de sinonímias. Assim, além da alienação, buscou-se mapear nos textos indicados também a presença das terminologias exteriorização e estranhamento. Não obstante, no decorrer das leituras, observou-se a presença das palavras autoalienação e desalienação que, em virtude da estreita relação existente entre estes termos e aqueles que foram definidas previamente, passaram a incorporar os parâmetros de buscas e análises. O mesmo ocorreu com as categorias fetichismo e reificação que, ao serem identificadas no contexto relacional com as categorias estudadas, também entraram nesse rol de análise. As buscas e as análises dessas categorias englobaram tanto o corpo dos textos como as notas de rodapé.

A partir da leitura dos artigos em que se identificou a presença das categorias citadas, ocorreu o processo de tabulação dos dados. Para a operacionalização dessa tarefa da pesquisa, elaborou-se uma tabela no programa MS Excel, que continha as seguintes informações: nome da revista; ano; volume; autor; título do artigo; citação na qual aparecia uma das categorias; a forma de uso da categoria; a categoria com a qual se relacionava; e a referência bibliográfica. Durante essa etapa, foi feita a leitura de todos os artigos selecionados, destacando-se, em cada um destes, trecho ou trechos que apresentavam alguma das categorias pesquisadas, identificando-se a forma como esta se apresentava e com qual categoria fazia relação, além de verificar se existia a referência bibliográfica que a fundamentasse. Quando, nos artigos analisados, apareciam mais de uma vez a mesma categoria ou categorias diferentes, elas eram organizadas na tabela levando em consideração a ordem de aparecimento no texto. Quando as categorias apresentaram um mesmo sentido, esses dados foram colocados juntos para não quebrar o sentido da explicação.

A partir da tabulação desses dados, foram realizadas reuniões entre os membros da pesquisa com o objetivo de determinar as possíveis formas de sua sistematização. Diante dos objetivos propostos no plano de trabalho e do tempo disponível para o restante da operacionalização da pesquisa, optou-se pelo encaminhamen- 
to de duas análises centrais: a identificação, a sistematização e a exposição das principais referências bibliográficas que lastreiam o uso da categoria da alienação nas revistas analisadas; e a identificação, a sistematização e a exposição das principais categorias que aportam relações com esses dados examinados. Assim, se, naquela análise, constam os autores e as referências teóricas que serviram de fundamento para o uso desta categoria, apontam-se, nesse segundo exame, vínculos teóricos que servem de elucidação para descortinar os conteúdos que se encontram por trás das citações dessa temática.

\section{b) Principais autores e referências bibliográficas identificadas:}

Sobre o primeiro quesito, dos autores e das obras teóricas incorporadas para referendar o uso da categoria da alienação, constatou-se que, em 59 artigos, o uso dessa categoria se fez sem nenhuma indicação direta de autores ou de referências bibliográficas. Nesses textos, a categoria da alienação foi, portanto, utilizada sem apresentar um fundamento teórico e bibliográfico que a referendasse. Assim, se a categoria da alienação apareceu em aproximadamente um (1) em cada cinco dos textos integrantes das 69 edições das revistas analisadas (em 121 dos 627 artigos), em quase a metade dos artigos em que se constatou a sua presença (59 dos 121 artigos) observou-se a omissão de uma fundamentação teórica que suportasse a sua utilização.

A desconsideração acerca da necessidade dessa fonte teórica pode provir de diversos fatores. Contudo, duas assertivas contraditórias e complementares podem ser relevadas: a assimilação corrente desse termo em variados espaços de formação teórica e profissional e o questionamento sobre a precisão teórica e metodológica da sua utilização. Esse paradoxo, no lugar de aparentar incongruência, expressa que a relevante presença da categoria da alienação nesses diversos ambientes é também catalisada pela amplitude heurística do seu uso. Por se tratar de um termo coloquialmente e correntemente utilizado, em que o seu uso remete a uma forma de externalidade crítica à ordem societária vigente e a condutas e valores moralmente admoestados, tal dinâmica acaba resvalando-se também em textos acadêmicos.

O uso da categoria da alienação marca presença em críticas ao capitalismo, assim como há expressões personificadas de condutores valorativos que servem para corroborar com esse sistema social. Essas críticas, por seu turno, se estabelecem e se baseiam em variados níveis de assimilação crítica e de fundamentação teórica, e a categoria da alienação transita livremente nesse espaço. Seus usos se remetem a diversos graus de incorporação de ideias e de referenciais críticos, desde os mais substantivos aos mais limitados. Da mesma forma, a sua utilização corrente e, até certo ponto, desmedida, pode indicar, ao autor que o incorpora, a não necessidade imediata de sua precisão teórica e metodológica. Por outro lado, a categoria da alienação é citada, também, como uma palavra que supostamente teria um sentido consensual e que, portanto, seria desnecessária a explicitação da sua fonte bibliográfica.

Não obstante, tal determinação também opera, mesmo com elementos distintos, na análise dos artigos em que foram indicadas as fontes bibliográficas dos usos desta categoria. Observando-se os 66 artigos em que foram explicitadas essas referências bibliográficas, percebe-se um amplo leque de autores citados e de obras referendadas. Ao todo compareceram, nos artigos analisados, 48 autores que foram utilizados como referências diretas aos usos da categoria da alienação. Destes autores, 40 foram citados apenas uma vez e o restante variou entre duas e 13 aparições.

O autor campeão e responsável pelo maior índice de aparecimento foi o fundador do materialismo histórico, que figura como o responsável pela constituição da categoria analisada: Karl Marx. Citado em 13 artigos como referência para esta categoria, Marx se fez presente nesse material através de seis referências bibliográficas. Conforme já era esperado, os seus Manuscritos Econômico-Filosóficos apareceram em primeiro lugar como principal obra de Marx usada para subscrever a categoria da alienação. E importante destacar que esse livro foi citado em diversas traduções. Além das traduções portuguesas, publicadas pela Edições 70 (MARX, 1993) e pela Editorial Avante (MARX, 1994), constaram duas traduções brasileiras: a publicada pela Editora Martin Claret (MARX, 2002) e a publicada pela Editora Boitempo (MARX, 2004). Por sinal, foi essa última edição a que mais apareceu, totalizando a metade das referências a essa obra. Tal fato, além de demonstrar a importância dada à tradução realizada por Jesus Ranieri (MARX, 2004), também indica a assimilação dos léxicos utilizados por esse tradutor: estranhamento x alienação ${ }^{5}$.

Por outro lado, ainda que esse tenha sido o livro de Marx mais citado, causa certa surpresa a quantidade de vezes em que os Manuscritos Econômico-Filosóficos foi usado como referência teórica da categoria analisada. Por representar, de forma indubitável, a principal obra em que o autor alemão tece comentários mais diretos sobre a categoria da alienação, esperava-se uma maior alusão a essa referência bibliográfica.

Figurando em segundo lugar, sendo referendado em três artigos, o Magnum Opus de Marx (O Capital) apareceu, na sua versão brasileira (MARX, 1987), também como uma fonte de referência para a categoria da alienação. Possivelmente, a visualização dessa obra como referencial teórico desta categoria tenha sido 
potencializada pelas escolhas de tradução, em que se preferiu verter os diferentes termos do vernáculo original (Entfremdung, Entäußerung e Veräußerung) para o mesmo léxico, de alienação. As outras obras do autor citadas, cada um com uma figuração, foram: Contribuição à Crítica da Economia Política; Crítica da Filosofia do Direito de Hegel; Sobre a Questão Judaica (MARX, 1973, 2006, 2010); e o livro escrito em parceria de Friedrich Engels, A Ideologia Alemã (MARX; ENGELS, 1987).

Em segundo lugar de utilização como fundamento da categoria da alienação, situou-se a destacada autora do Serviço Social brasileiro, Marilda Iamamoto. O livro dessa autora (IAMAMOTO, 2007), intitulado Serviço Social em Tempo de Capital Fetiche, que apareceu cinco vezes, só foi menos citado que o livro de Marx de 1844. Além disso, duas outras obras de Iamamoto $(2009,2014)$ também estiveram presentes na análise: O Serviço Social na Cena Contemporânea e A Formação Acadêmico-Profissional no Serviço Social Brasileiro, sendo o primeiro citado em dois artigos e o segundo em um (1). Tal fato demonstra que, em analogia a outras temáticas, Iamamoto (2007) também representa, dentro do estudo da alienação, uma das principais referências teóricas utilizadas no Serviço Social no Brasil, sendo tal fato ampliado a partir da publicação do seu livro mais recente.

Dois outros autores brasileiros, também inseridos em debates e presentes em formações teóricas e profissionais do Serviço Social, se destacaram na análise: Maria Lúcia Barroco e Carlos Nelson Coutinho. Dois livros de Barroco $(2003,2010)$, que se constituem como referências centrais dentro do Serviço Social brasileiro para o estudo da temática da ética foram citados: Ética: fundamentos sócio-históricos e Ética e Serviço Social: fundamentos ontológicos. Respectivamente citados em dois e um (1) textos. Entretanto, pela ligação direta existente entre as análises divulgadas da autora e o exame da categoria da alienação, essa quantidade de citações aparentou ser bastante diminuta. Pela conexão com a análise dessa temática, cogitavase uma maior utilização de obras dessa autora.

Já em relação a Coutinho, ainda que esse autor tenha publicado variadas obras que tenha abordado autores e estudos relacionados à temática da alienação (especialmente quando ele aproximou-se da perspectiva de György Lukács), as suas obras indicadas como referências para esta categoria foram de ordem diversa: Representações de Interesses, Formulação de Políticas e Hegemonia e Gramsci: um estudo sobre seu pensamento (COUTINHO, 1989, 1999). Com isso, como será indicado mais à frente, constata-se que as escolhas das suas obras para lastrear a categoria da alienação irradiaram-se mais perante o complexo da política do que em relação às mediações entre trabalho e ser social.

Por outro lado, foi do seio da tradição lukacsiana que aparecem algumas referências que fundamentam a utilização da categoria analisada. Isso ocorreu tanto em obras escritas por Lukács, que contou com três citações, como de dois pensadores famosos que seguiram a sua esteira: István Mészáros, figurando seis vezes, e Agnes Heller, que apareceu em número igual ao seu antigo mestre. As citações de Lukács (1981) advêm da edição italiana da sua Ontologia do Ser Social, o que demonstra não apenas uma maior proximidade com a fase madura desse pensador (em detrimento do seu livro mais famoso História e Consciência de Classe), como indica que a referência à versão italiana deve ter sido realizada por especialistas em seu pensamento. No caso de Mészáros (2006), o seu livro que trata especificamente do tema em tela, A Teoria da Alienação em Marx, apareceu em destaque, sendo citado em qua-

Com isso, se, de um lado, se estabelece uma mediação entre esses dois complexos - o pensamento marxista e 0 Serviço Social brasileiro acerca da incorporação e da utilização da categoria da alienação, de outra forma, resta 0 questionamento acerca do grau e do teor desta vinculação, precisando-se quais as linhagens teóricas e metodológicas que estariam mais presentes nessas citações. tro artigos. Já a sua obra mais importante (MÉSZÁROS, 2002), Para Além do Capital, apareceu em duas oportunidades. Em relação à Agnes Heller (1989, 1991), ressalta-se que suas obras citadas se referem à fase em que esta pensadora ainda orbitava na tradição marxista e explicitavase na linhagem de seu ex-mestre: O Cotidiano e a História e Sociologia de la Vida Cotidiana.

Todavia, é fato paradoxal que, apesar do relevo dado a obras e ideias integrantes da perspectiva lukacsiana, nem as edições brasileiras de obras de Lukács foram citadas, nem alguns dos principais difusores das ideias desse autor dentro do Serviço Social brasileiro tiveram destaques. Nenhuma referência a José Paulo Netto foi identificada nos artigos analisados. Ainda que o livro central em que José Paulo Netto aborde nuclearmente a 
categoria da alienação (Capitalismo e Reificação) tanto se requeira uma leitura mais aprofundada, como tenha ficado um bom tempo esgotado ${ }^{6}$, é fato que ele também trata desse tema - de forma direta ou não - em várias outras obras. Contudo, em nenhum momento as referências de Paulo Netto foram utilizadas para subscrever a utilização da categoria da alienação. Análogo a isso foi o que aconteceu com outro destacado autor, talvez atualmente o mais expressivo dentro do debate do Serviço Social brasileiro acerca da temática da alienação: Sérgio Lessa. O nome desse autor apareceu apenas uma vez, ao lado de Ivo Tonet, por meio da referência ao seu livro Introdução à Filosofia de Marx (LESSA; TONET, 2011).

Para além dos autores aqui elencados, as citações ocorreram em um longo diapasão que, mesmo sendo tangenciadas pela tradição marxista, abarcaram um escopo bem extenso. Dentro desse campo, foram enunciados nomes como Antonio Gramsci, Nicolas Tertulian, José Chasin, Leandro Konder e Mauro Iasi. As indicações também transitaram por autores de quilate mais heterodoxo, mas que, de forma direta ou não, tiveram uma relação com o marxismo, como Pierre Bourdier e Paulo Freire. Por outro lado, também apareceram referências de autores claramente distanciados dessa perspectiva teórica, como Boaventura de Sousa Santos, Domenico De Masi e Edgar Morin. Ainda que figurem em menor expressão, a utilização destes três últimos autores como forma de fundamentar o uso da categoria da alienação demonstra quão larga é a angulação dessa utilização, abarcando até mesmo autores que afrontam a concepção teórica e metodológica inaugurada por Karl Marx.

\section{c) Principais sentidos e usos analisados:}

Já no que concerne às formas de uso da categoria da alienação, objetivou-se tecer relações entre essa temática e algumas variáveis que, nos artigos analisados, mais se aproximaram dela. Em ordem decrescente de aparecimento, foram quatro os quadrantes que serviram para englobar e classificar as variações das formas e dos usos mais figuradas sobre essa categoria: alienação política; alienação ao trabalho; alienação subjetiva; e alienação metodológica.

A alienação política foi bastante expressa, apresentando-se, especialmente, a partir de uma relação com críticas ao Estado capitalista e à falta de consciência dos direitos sociais. A ausência de uma consciência por parte das pessoas, que as conduzisse a uma visualização dos direitos sociais como uma determinação social e não como um favor seria não somente uma das razões da existência da alienação, mas também um dos objetos a serem combatidos pelos assistentes sociais. Da mesma forma, o Estado apareceu como um instrumento do capital que, ao atuar nas esferas da dominação e da legitimação da ideologia vigente, se constituiria como um núcleo alienador. Em sentido análogo a própria política apareceu como um instrumento de opressão e de desumanidade, apontando-se para a necessidade da democratização do Estado.

Também na seara da alienação política outras admoestações sociais se fizeram presentes, desde críticas ao conformismo social, passando-se pela indicação de ausência de uma consciência social, e apontando-se para o caráter instrumental dos direitos sociais, por se encontrarem subsumidos ao mercado capitalista. Essa forma de alienação também se apresentaria como uma determinação da questão social e que, nesse sentido, deveria ser combatida pelos assistentes sociais. Como possibilidades de combate à vigência da alienação política, deveriam ser incentivadas formas de participação e de integração social, de desvelamento das naturezas dos mecanismos dominantes e do resgate do potencial crítico da classe trabalhadora, qualidade que teria sido perdida a partir da precarização do trabalho.

Neste sentido, a principal expressão da alienação se daria no campo político e teria três relações centrais: com o estabelecimento da ideologia dominante, com a falta de consciência acerca dos direitos sociais e com a precarização do trabalho. Se naqueles dois elementos a alienação seria superada pela efetivação da participação social e pela real vigência dos direitos sociais ou, em último caso, pela destruição do Estado (operando como aparelho de opressão social), a sua relação com a precarização do trabalho requereria a ligação com outro complexo social. Com esse último elemento, à alienação política conjuga-se uma dinâmica análoga, mas, com legalidade referente à esfera do trabalho.

A alienação do trabalho foi expressa a partir da precarização das condições de trabalho agravadas pelas contrarreformas do Estado neoliberal. Na visão destes autores não somente o estabelecimento de políticas neoliberais deveria ser visto como um agravante da alienação como, em alguns casos, apontar-se-ia uma relação de causalidade entre esses fenômenos.

Em outros momentos, a alienação do trabalho apareceu de forma mais categórica, como um resultado imanente da transformação da força de trabalho em mercadoria. Contudo, também foram detectados elementos que romantizaram essa determinação, indicando que teria sido o distanciamento com a natureza a real fonte da vigência desse fenômeno. Nessa perspectiva, indicou-se a adoção do desenvolvimento sustentável como superação para a alienação. De forma análoga, a simples aquisição de meios de produção conduziria os 
trabalhadores à superação da alienação e, num mesmo número de textos, a autogestão, típico modelo gestionário de empreendimentos econômicos cooperativos, seria capaz de erradicar completamente esse fenômeno. Contudo, ainda que conste que essas experiências seriam capazes de suplantar a desumanização da economia, por outro lado, também se indicou que experimentos tais como as cooperativas, ao ampliar as disputas entre os seus integrantes, se configurariam como gendarmes da alienação.

As terminologias utilizadas para definir a relação da alienação com o trabalho também comportou variações. Apareceram desde a crítica à expropriação e à manipulação do trabalho alheio, o rechaço a uma condição moral que não permitiria o reconhecimento dos produtos, passando pela opressão realizada contra o trabalhador e a gradativa degradação da sua vida pela mercadoria, até se chegar ao estabelecimento do ócio como forma de evitar a alienação do trabalho e do tempo livre. Também se fizeram presentes algumas especificidades da categoria profíssional dos assistentes sociais, quando se sugeriu que a relação entre estagiário e supervisor, por ser provisória, não seria alienada. Analogamente, certificou-se que o estágio do assistente social não é alienação porque se aportam conhecimentos da vida profissional.

Nos artigos analisados, a relação da alienação com os processos de trabalhos, ainda que resguarde uma ligação com o espaço produtivo, desborda essa fronteira em direção a variadas temáticas. Poucas especificidades e profundidades teóricas foram identificadas na análise desse campo, vislumbrando-se mais as suas ilações correlativas do que a sua precisão categorial. A indicação analítica do trabalho ou da força de trabalho veio acompanhada menos por uma fundamentação teórica que endossasse a crítica da economia política, realizada por Marx, e mais por uma miríade de indicações ilativas que perpassam a relação com a natureza, os processos hierárquicos e organizacionais, assim como as relações contratuais de estágio. Assim, se, de um lado, observase a imbricação entre as categorias de trabalho e de alienação, por outro lado, essas mediações podem chegar a um escopo tão elevado que faz evanescer essa ligação. Além disso, a própria representação da alienação a partir da sua relação com a subjetividade humana termina por resvalar em desconsideração da sua ligação com o próprio complexo do trabalho.

A alienação da subjetividade aparece, nos artigos analisados, essencialmente como um expoente do individualismo. O consumismo imposto pela classe dominante terminaria por constituir as bases da alienação a tal ponto que poderia ocorrer a perda ou a captura da subjetividade do ser humano. Em caso similar, a marca da alienação encontrar-se-ia no fato da subjetividade, dentro da sociedade capitalista, ter se transformado em mercadoria. A fonte desse fenômeno seria o mercado e se isso levaria ao individualismo e ao consequente distanciamento dos indivíduos do gênero humano, por outro lado, o mercado, por meio de repressões econômicas e políticas, seria o grande responsável pelos entraves à liberdade humana. Irradiando-se na esfera da consciência humana, a alienação apareceu tanto como um fenômeno psíquico-cultural, como foi expresso falta de consciência de que as pessoas são seres históricos e não apenas objetos passivos que foram coisificados.

Essa falta de consciência também se aproxima da análise anterior, sobre a categoria do trabalho, sendo apresentada através dos obstáculos gerados à consciência de classe dos trabalhadores, que, no lugar de buscarem uma unidade, estariam competindo entre si. Outro problema, que serviria de fundamento para a alienação e que também envolveria os assistentes sociais, seria a sobrecarga de trabalho. Não obstante, o acúmulo de afazeres e de atividades ora aparece como catalizador da alienação, ora como a própria causa fundante desse fenômeno.

Também se destacaram variadas expressões da vigência da alienação, como a ausência de criatividade e de capacidade reflexiva; a falta de controle dos indivíduos, advinda da sociedade de risco; e o aparecimento de problemas psíquicos gerados por perdas de vínculos sociais. Tanto os problemas emocionais, como a deformação psíquica do trabalhador seriam qualidades de destaque da alienação. E, diante dessa complexidade de sentidos correlacionados com a alienação, o próprio trabalho aparece numa ambivalência: ora é utilizado como categoria determinante de crítica à subjetividade subsumida ao capital, seja vinculada à falta de consciência do trabalhador ou à venda da força de trabalho, ora é figurado, paradoxalmente, como um elemento endógeno à própria subjetividade, estando o trabalho constituindo-se como um elemento subjetivo do corpo, que the foi alienado.

Finalmente, a alienação também aparece, nos artigos analisados, vinculada a nuances metodológicas. A alienação ocorreria a partir do momento em que o assistente social contempla a realidade social por meio do senso comum, da imediaticidade e da naturalização do cotidiano. Esses elementos seriam, pois, obstáculos a um pensamento crítico que, por sua vez, poderiam conduzir à responsabilização dos indivíduos pelos seus problemas sociais. Impossibilitados de analisar a realidade a partir de uma perspectiva de totalidade social, não seria possível identificar as mediações históricas presentes no desenvolvimento da humanidade, tratando as pessoas como agentes passivos. Essa dinâmica alienadora poderia ser exemplificada a partir do caso dos pacientes médicos que são tratados como objetos passivos.

Em relação mais direta com a ciência e com a universidade, a alienação aparece como sinônimo de tecnicismo e, de maneira semelhante, como categoria correlativa à separação entre teoria, prática e intervenção política (e que apenas serviria para legitimar o capital). A ausência de pensamento crítico, seja adotado 
pelo pesquisador, seja confluente na academia, também fermentaria a alienação. A qualidade autônoma dessa instituição (a universidade), contudo, apareceu criticamente analisada, seja por se distanciar dos problemas sociais, seja por consubstanciar-se em um conhecimento em direção única. A própria palavra autonomia recebeu, por seu turno, a sua carga de admoestação. A análise da autonomia, ao ser tratada de forma isolada, e não por uma ligação umbilical com a heteronomia, também representaria uma forma de alienação.

Ressalta-se, por fim, a presença da palavra estranhamento em um sentido inovador e, até mesmo, de maneira demasiada distante da categoria da alienação. Buscou-se apontar para o fato de que, quando ocorre um estranhamento entre o pesquisador perante o seu objeto de estudo, isso demarca não somente a incapacidade cognitiva, teórica e intelectual do pesquisador, como determina a vigência da alienação. Por outro lado, a palavra estranhamento referiu-se a um sentido inverso, indicando o momento de espanto perante uma coisa nova e que, dessa forma, serve para desnaturalizar a realidade. Se, naquele caso, o estranhamento é vinculado à incapacidade de análise, nesse, a mesma palavra serve de catalizador do desenvolvimento do conhecimento 7 .

\section{Considerações finais}

Apesar das limitações dos dados analisados, restritos a 69 edições de dois periódicos nacionais da área de Serviço Social, pode-se ressaltar que a categoria da alienação detém uma grande importância teórica. Sendo citada em um de cada cinco artigos publicados no universo de análise, a sua forte presença é inconteste. Fato esse que pode ser facilmente transladado para outros espaços e documentos de formação do Serviço Social brasileiro. O seu amplo uso vem acompanhado também por um amplo escopo heurístico. Diversos foram os autores e variadas foram as formas de uso detectadas e que suportam e acompanham a citação desta categoria. A expressão da categoria da alienação aporta relações distintas e, mesmo com a delimitação das quatro categorias aqui elegidas para essa mediação de análise (política; trabalho; subjetividade; e método), não foi possível dar conta da amplitude do seu uso.

Identificou-se, todavia, uma maior proximidade da sua utilização com os complexos da política e do trabalho. Especialmente detectou-se a sua presença na sua relação com a participação política e com a cobrança dos direitos sociais, assim, como com a precarização do trabalho. Mesmo assim, não se pode desconsiderar que, principalmente na correlação com a subjetividade, como com o método, o uso da categoria da alienação foi excessivo, extrapolando uma circunscrição teórica e analítica. Uma categoria que é usada de demasiadas formas, corre o risco de perder a precisão da sua capacidade expositiva.

Em relação às fontes que referendaram o seu uso, é possível afirmar que o maior relevo se encontra em autores e obras que orbitam na tradição marxista. Não somente mais da metade dos autores referendados possui relações diretas com essa perspectiva teórico-metodológica, como as obras que mais apareceram nas análises são relativas a clássicos do pensamento marxista. Mesmo que, surpreendentemente, tenham aparecido alguns autores distantes e mesmo adversários desse campo, a hegemonia marxista se fez presente. Ao menos nos dados quantitativos das referências bibliográficas.

Quanto ao teor da assimilação e do uso dessas bibliográficas oriundas da tradição marxista, pode-se indicar uma analogia com o título deste artigo. Sob o casaco de Marx? Possivelmente sim. Mas apenas na medida da condicionalidade da oscilação de posse que esse objeto teve.

\section{Referências}

ALTHUSSER, L. Pour Marx. Paris: Maspero, 1965.

BARROCO, M. L. S. Ética e serviço social: fundamentos ontológicos. 2. ed. São Paulo: Cortez, 2003.

BARROCO, M. L. S. Ética: fundamentos sócio-históricos. 3. ed. São Paulo: Cortez, 2010.

COUTINHO, C. N. Gramsci: um estudo sobre seu pensamento político. Rio de Janeiro: Civilização Brasileira, 1999.

COUTINHO, C. N. Representação de interesses, formulação de políticas e hegemonia. In: TEIXEIRA, S. F. (org.). Reforma sanitária: em busca de uma nova teoria. São Paulo: Cortez, 1989. p. 47-60.

FEUERBACH, L. A essência do cristianismo. 4. ed. Petrópolis: Vozes, 2013.

FREDERICO, C. O jovem Marx: as origens da ontologia do ser social. São Paulo: Cortez, 1995.

FROMM, E. Conceito marxista de homem. 4. ed. Rio de Janeiro: Zahar, 1967.

GIANNOTTI, J. A. Origens da dialética do trabalho. São Paulo: Difusão Europeia do Livro, 1966.

HEGEL, G. W. Fenomenologia do espirito. Petrópolis: Vozes; Bragança Paulista: Editora Universitária São Francisco, 1992. (Coleção Pensamento Humano).

HELLER, A. O cotidiano e a história. São Paulo: Paz e Terra, 1989. 
HELLER, A. Sociología de la vida cotidiana. Barcelona: Peninsula, 1991.

IAMAMOTO, M. A formação acadêmico-profissional no Serviço Social brasileiro. Serviço Social \& Sociedade, São Paulo, n. 120, p. 609-639, out./dez. 2014.

IAMAMOTO, M. O Serviço Social na cena contemporânea. In: CONSELHO FEDERAL DE SERVIÇO SOCIAL; ASSOCIAÇÃO BRASILEIRO DE ENSINO E PESQUISA EM SERVIÇO SOCIAL (org.). Serviço Social: direitos sociais e competências profissionais. Brasília, DF: CFESS: ABEPSS, 2009. p. 15-50.

IAMAMOTO, M. Serviço Social em tempo de capital fetiche. São Paulo: Cortez, 2007.

LESSA, S.; TONET, I. Introdução à filosofia de Marx. 2. ed. São Paulo: Expressão Popular, 2011.

LUKÁCS, G. Ontologia dell'essere sociale II. Roma: Riuniti, 1981.

MARX, K. Contribuição para a crítica da economia política. Lisboa: Estampa, 1973.

MARX, K. Crítica da filosofia do direito de Hegel. São Paulo: Boitempo, 2006.

MARX, K. Das Kapital. Kritik der politischen Ökonomie. Erster Band, Buch I: Der Produktionsprozeß des Kapitals. In: MARX, K.; ENGELS, F. Werke. Band 23. Berlim: Dietz Verlag, 1962. p. 49-802.

MARX, K. Manuscritos econômico-filosóficos de 1844. In: MARX, K. Cadernos de Paris \& manuscritos econômico-filosóficos de 1844. São Paulo: Expressão Popular, 2015. p. 237-445.

MARX, K. Manuscritos económico-filosóficos de 1844. Lisboa: Avante!, 1994.

MARX, K. Manuscritos económico-filosóficos. Lisboa: 70, 1993.

MARX, K. Manuscritos econômico-filosóficos. São Paulo: Boitempo, 2004.

MARX, K. Manuscritos econômico-filosóficos. São Paulo: Martin Claret, 2002.

MARX, K. O capital: crítica da economia política. São Paulo: Bertrand Brasil, 1987. v. 1.

MARX, K. Sobre a questão judaica. São Paulo: Boitempo, 2010.

MARK, K.; ENGELS, F. A ideologia alemã. São Paulo: Hucitec, 1987.

MÉSZÁROS, I. A teoria da alienação em Marx. São Paulo: Boitempo, 2006.

MÉSZÁROS, I. Para além do capital. São Paulo: Boitempo, 2002.

PAULO NETTO, J. Capitalismo e Reificação. São Paulo: Ciências Humanas, 1981.

PAULO NETTO, J. Capitalismo e Reificação. São Paulo: ICP, 2015.

\section{Notas}

1 Um grande passo dado por Marx em relação ao trato da alienação, que foi possibilitado pela assimilação crítica do pensamento materialista de Feuerbach (2013), foi ter distinguido esse termo das categorias de objetivação e de exteriorização, que apareciam como sinônimos na obra juvenil deHegel(1992).

2 Conforme detalhado mais à frente, ressalta-se tanto que a análise realizada buscou verificar se os usos e as referências dadas à categoria da alienação foram relacionados ou não com as obras de Karl Marx, como, também, se essas configurações se lastrearam metodologicamente por determinações econômicas.

3 Ainda que as três palavras indicadas (Entfremdung, Entäußerung e Veräußerung) possam ser utilizadas pela mesma terminologia (da alienação), como o faz, em grande medida, as traduções inglesas, ocorreu, no Brasil, uma contenda em torno das suas traduções. Se, em Marx (2002), por exemplo, Entfremdung é traduzido por alienação e Entäußerung por exteriorização, em Marx (2004), se inverte as ligações e é Entäußerung quem é traduzido por alienação, passando Entfremdung a ser chamado de estranhamento.

4 As duas revistas - Revista Katálysis e Serviço Social \& Sociedade - são classificadas, pela escala avaliativa da Qualis/CAPES, como A1, que expressa um nível de elevada qualidade internacional.

5 Conforme indicado em nota anterior, diferentemente da outra obra brasileira citada, em que os termos Entfremdung e Entäußerung foram traduzidos, respectivamente, por alienação e exteriorização, Ranieri (MARX, 2004) optou por uma inversão nos sentidos teóricos e traduziu os termos citados por estranhamento e alienação.

6 Entre a publicação da primeira edição (PAULO NETTO, 1981) que ocorreu pela Editora Ciências Humanas em 1981, e a segunda (PAULO NETTO, 2015), realizada pelo Instituto Caio Prado Júnior em 2015, existiu um período de 34 anos. Esgotado por muitos anos, esse livro se encontrou, por muito tempo, praticamente inacessível ao grande público.

7 Outras duas relações pontuais se apresentaram nos artigos analisados: a alienação relacionada a modos de vida e a alienação na sua especificidade da alienação parental.

\section{Henrique Wellen}

harw@uol.com.br

Doutorado em Serviço Social pela Universidade Federal do Rio de Janeiro (UFRJ)

Professor Associado do Departamento de Serviço Social da Universidade Federal do Rio Grande do Norte (UFRN) 
Julliane Trindade Oliveira

julli.trindade@gmail.com

Graduanda em Serviço Social pela Universidade Federal do Rio Grande do Norte (UFRN)

Miliane Pinheiro Rocha

milianerochap@outlook.com

Graduanda em Serviço Social pela Universidade Federal do Rio Grande do Norte (UFRN)

\section{UFRN}

Departamento de Serviço Social

Av. Sen. Salgado Filho, 3000 - Lagoa Nova

Natal - Rio Grande do Norte - Brasil

CEP: $59.078-970$

\section{Agência financiadora}

A pesquisa contou com bolsa de iniciação científica do PIBIC/ UFRN (PVE14131-2017) do Conselho Nacional de Desenvolvimento Científico e Tecnológico (CNPq), de agosto de 2017 a julho de 2018.

\section{Contribuições dos autores}

A pesquisa e a escrita do artigo foram realizadas de forma conjunta pelos três autores.
Aprovação por Comitê de Ética e consentimento para participação

Não se aplica.

Consentimento para publicação

Não se aplica.

\section{Conflito de interesses}

Não há conflito de interesses. 